\title{
SOBRE LA VALIDEZ TEMPORAL DE LAS NORMAS. LA RETROACTIVIDAD Y ULTRAACTIVIDAD DE LAS NORMAS EN EL SISTEMA JURÍDICO
}

\author{
Carla HUERTA OCHOA
}

\section{Resumen:}

La validez temporal de las normas se vincula a los principios de legalidad y seguridad jurídicas. La capacidad de una norma de operar de manera diferenciada en el tiempo se fundamenta, asimismo, en razones de certeza jurídica y de justicia. El tema de la retroactividad es analizado con el objeto de comprender su naturaleza, fines, limites y alcances como institución jurídica, no solamente para entender su función en el sistema jurídico, sino también para hacer evidente que esta forma de aplicación de las normas no atenta contra las ideas de unidad y coherencia del sistema jurídico.

\section{Abstract:}

Temporal validity of norms is tied to due process and legal certainty principles. Likewise, a norms possibility to be applied at different moments in time is based in certainty and fairness principles. It is with this background and framework that the subject of retroactivity is addressed, understanding its nature, aims and reach, arguing that this form of application of norms does not undermine the unity and coherence of a legal system. 
SUMARIO: I. Introducción. II. El tiempo en la operatividad del sistema juridico. III. La validez temporal de las normas jurídicas. IV. Validez temporal y artículos transitorios. V. La retroactividad. VI. Conclusión.

\section{INTRODUCCIÓN}

Muchos son los problemas que en la actualidad hacen considerar a los sistemas jurídicos como incomprensibles, contradictorios, voluminosos o incluso absurdos. Su excesivo crecimiento ha tenido como consecuencia que el volumen de normas que lo integran no sea manejable. Uno de los efectos de su exagerado desarrollo ha sido no solamente la imposibilidad de conocer el universo de normas aplicables, sino también una serie de deficiencias que dificultan la operatividad del sistema jurídico tales como la redundancia, la incoherencia y la inconsistencia del mismo, ${ }^{1}$ independientemente, de que a pesar de la sobreabundancia de normas, no es posible afirmar que el sistema jurídico de hecho sea completo.

Desgraciadamente, éstos no han sido los únicos efectos, también se ha producido una serie de disposiciones juridicas de dudosa legalidad y constitucionalidad, que dificilmente pueden ser ubicadas en ninguna de las categorias normativas existentes, ni ordenarlas jerárquicamente de manera adecuada. Otros vicios se han producido, como desvirtuar la naturaleza de ciertas instituciones jurídicas y utilizarlas de manera arbitraria para lograr fines específicos o subsanar errores, como es el caso de los artículos transitorios.

En esta ocasión me ocuparé solamente de un problema específico relacionado con la validez en el tiempo de las normas jurídicas, analizando la función y alcance de las determinaciones especiales de validez temporal, como son la re-

1 Bulygin, "Teoría y técnica en la legislación", Análisis lógico y derecho, Madrid, Centro de Estudios Constitucionales, 1991. 
troactividad y la ultraactividad, así como del objeto y la oportunidad de la aplicación retroactiva de las normas.

La validez temporal de las normas se refiere en primera instancia a su vigencia y en segunda, a la pérdida de la misma, ya sea por derogación o anulación de la norma. Estas dos cuestiones se refieren básicamente a las reglas de introducción y eliminación de las normas de un sistema jurídico, al lado de las cuales existen reglas relativas a las dos formas de operatividad extraordinaria de las normas que se refiere al ámbito de validez temporal de las mismas.

\section{EL TIEMPO EN LA OPERATIVIDAD DEL SISTEMA JURÍDICO}

El conocimiento del funcionamiento de un sistema juridico es relevante para el presente análisis en la medida en que puede explicarnos como se justifica y opera la retroactividad, su relación con los artículos transitorios, así como con otro tipo de normas como son las derogatorias, en la medida en que estas normas determinan la validez temporal de otras normas. Es relevante también el estudio de la jurisprudencia tanto para averiguar si puede operar retroactivamente, como para conocer las determinaciones que la jurisprudencia ha hecho al respecto en el caso del derecho positivo mexicano.

El punto de partida es una concepción del derecho como un sistema jurídico dinámico, en virtud de lo cual se encuentra en un constante proceso de modificación, y a cuya esencia corresponden ciertas reglas de cambio, funcionamiento, aplicación e interpretación. Estas reglas se encuentran en las normas jurídicas, ya sea en la Constitución, las leyes o la jurisprudencia, su explicación, sin embargo, debe ser proporcionada por la teoría del derecho.

La capacidad de las normas jurídicas para producir efectos sólo puede ser entendida a partir de la operatividad del propio sistema jurídico, ya que como elementos fundamentales del mismo se ven determinadas por su funcionamiento. El modelo que considero adecuado para comprender la 
validez temporal de las normas y en especial, la razón de ser y operatividad de la retroactividad, es el que se basa en la distinción material entre sistema y orden jurídicos. ${ }^{2}$ No se trata de una mera distinción conceptual, sino de dar a estos términos, que en general son utilizados como sinónimos, un significado propio. No obstante, y en virtud de lo anterior, cabe aclarar que en la teoria del derecho no se ha adoptado un uso convencional de dichos términos, por lo que debido a las propiedades de cada una de estas entidades normativas, se ha optado por utilizar el término "sistema" para referirnos a la totalidad de las normas juridicas que conforman un derecho, y el de "orden" para hacer las distinciones temporales necesarias para analizar la validez temporal de las normas como a continuación se explica.

Hacer esta distinción es posible en función de la naturaleza dinámica del derecho, ya que el sistema regula sus modos de creación y modificación conforme a los procedimientos que el mismo prevé. Una de las cualidades distintivas del derecho es precisamente su capacidad de autorregulación. Por ello es que Hart ${ }^{3}$ distingue dos tipos de normas, las que regulan conductas (normas primarias), y las que se refieren a esas normas y a los órganos de creación y aplicación (normas secundarias). Hart incluye dentro de la clase de las normas secundarias a la regla de reconocimiento, que sirve como criterio de identidad y permite determinar las normas que pertenecen al sistema, a las reglas de cambio, que regulan sus procesos de modificación y las reglas de adjudicación que establecen los órganos y procedimientos de aplicación.

De conformidad con la clasificación de Hart, se puede afirmar que existe un tipo de reglas que tienen como función regular las conductas de los individuos, y otro que se

2 Véase Alchourrón y Bulygin, Introducción a la metodología de las ciencias juridicas y sociales, Buenos Aires, Astrea, 1993, passim; Huerta, Carla, Conflictos normativos, México, UNAM, Instituto de Investigaciones Jurídicas, 2003, pp. 23-35; Raz, Joseph, El concepto de sistema jurídico, México, UNAM, 1982, pp. 221-236.

3 Hart, El concepto de derecho, Buenos Aires, Abeledo Perrot, 1992, pp. 99 y ss. 
dirige a las autoridades. Este segundo grupo puede subdividirse en aquéllas cuya función es atribuir competencias y las que determinan el modo de aplicación de otras normas. Estas distinciones tienen por objeto demostrar que las normas jurídicas, aunque todas regulan conductas, pueden ser distinguidas en función del sujeto a quienes se dirigen, así como por su objeto. Admitir una distinción entre diversos tipos de reglas, no justifica; sin embargo, negar a ninguno de ellos su carácter prescriptivo, ya que ambos tipos de normas establecen un deber ser. Son normas cuya contravención será calificada por el sistema jurídico como ilícita.

La noción de sistema jurídico se funda en la relación de sus elementos ya que forman una unidad, la estructura que deriva de esta concepción determina su operatividad. La diferencia entre sistema y orden jurídicos se basa en la posibilidad de distinguir temporalmente la totalidad de las normas jurídicas de conjuntos específicos delimitados temporalmente. ${ }^{4}$ Así, la diacronía sería característica de las normas que integran al sistema jurídico, es decir, se identifican por su operatividad a través del tiempo (hacia el futuro o el pasado), y por la posibilidad de aplicar en casos específicos normas no vigentes. Esto se debe a que al sistema pertenecen, no solamente las normas vigentes, sino también las normas que ya han sido derogadas, pues aunque parezca contradictorio, siguen perteneciendo al sistema. Por lo que el criterio definitorio del sistema jurídico es el de pertenencia.

El sistema jurídico se conforma entonces, por la totalidad de las normas que se correlacionan en virtud de la unidad que integran a partir de la Constitución, y se compone por una secuencia de conjuntos de normas vigentes en momentos distintos, identificables temporalmente por los cambios en el conjunto de normas jurídicas generales. El orden jurí-

4 El primer antecedente de esta distinción se encuentra en la obra de Joseph Raz, quien distinguió el "sistema jurídico" de los "sistemas jurídicos momentáneos", El concepto de sistema jurídico. Una introducción a la teoría del sistema juridico, traducción de Rolando Tamayo y Salmorán, México, UNAM, 1986, pp. 221-236. 
dico constituye cada uno de esos conjuntos de normas vigentes en un momento específico, el cambio de un orden a otro se da cada vez que se introduce o elimina una norma jurídica general. 5

Es importante mencionar que al sistema jurídico pertenecen, además de las normas jurídicas, sus consecuencias lógicas válidas conforme a las reglas del sistema. ${ }^{6}$ La aplicabilidad de las normas depende de la determinación temporal del caso y del orden jurídico vigente, tanto en el momento en que ocurrieron los hechos, como en el de la emisión de la resolución por parte de la autoridad competente. En ocasiones, el sistema jurídico permite temporalmente, y de manera excepcional, la aplicación de normas que ya no están vigentes. Esto es posible porque la derogación no afecta la pertenencia de una norma al sistema, sino su vigencia, por lo que deja de formar parte de los órdenes jurídicos sucesivos a partir del momento de su derogación o abrogación, pero aun integra el sistema jurídico.

El criterio de validez de las normas no sirve para identificar al sistema, sino para determinar la aplicabilidad de sus normas, en consecuencia, sirve más bien para identificar al orden jurídico, que a diferencia del sistema jurídico, es sincrónico. El orden jurídico representa al conjunto de normas que tienen aplicación simultánea en un momento determinado, ya que el orden se refiere a las normas vigentes. E1 concepto de aplicabilidad es más amplio, ya que incluye a las normas que por disposición expresa se reputan válidas

5 Solamente las normas jurídicas generales podrán producir el cambio de orden jurídico, para ello se requiere que no solamente cambie la formulación, sino que en verdad se trate de otra norma, introducir una norma que ya se encuentra en el sistema, por ser redundante, no produciría el cambio. La jurisprudencia, sin embargo, por ser el significado de una norma, si produce el cambio, ya que a pesar de que la formulación de la norma interpretada no varia, la norma si se modifica. Sobre esto último se abunda en el cuarto apartado en relación con la mutación de la jurisprudencia.

6 Esta tesis es sostenida por Alchourrón y Bulygin, quienes definen al sistema normativo como "un conjunto de enunciados tales que entre sus consecuencias hay enunciados que correlacionan casos con soluciones. Todo conjunto normativo que contiene todas sus consecuencias es pues, un sistema normativo"; Introducción a la metodología de las ciencias jurídicas y sociales, cit., nota 2, p. 92. 
para resolver un caso a pesar de que su operatvidad en el tiempo sea retroactiva o ultraactiva.

La vigencia de las normas depende de las determinaciones que el propio sistema jurídico hace de manera general en alguna de sus normas o específicamente en algún artículo transitorio, hasta que sea eliminada del orden juridico, ya sea por vía de derogación o supresión de su validez. ${ }^{7}$ Las normas vigentes son obligatorias y vinculantes, su aplicabilidad deriva del reconocimiento por el sistema de su existencia de manera plena, por lo que pueden producir efectos jurídicos. Para Bulygin ${ }^{8}$, la vigencia consiste en la disposición de la norma de ser aplicada, por lo que podríamos decir que sólo es posible o potencial, mas no necesaria.

La noción de orden jurídico sirve para identificar el conjunto de normas vigentes en una fecha específica, lo cual permite determinar cuáles son las normas aplicables a un caso determinado. ${ }^{9}$ Como modelo es estático, puesto que al cambiar una sola norma general cambia el orden jurídico, o en otras palabras, el conjunto de normas aplicables.

La distinción entre sistema y orden jurídicos es fundamental para la determinación de las normas aplicables a un caso, una vez revisadas las reglas de competencia y los procedimientos de creación y eliminación de las normas, ya que la movilidad en el tiempo se producirá a partir de la determinación de la vigencia y la validez de la norma. Esto permite verificar las disposiciones relativas a la operatividad de las normas en el tiempo con el objeto de evitar la

7 Bulygin utiliza la distinción temporal que él llama "tiempo interno y tiempo externo" para explicar las relaciones de existencia y vigencia de las normas, principalmente en relación con las disposiciones transitorias y su modificabilidad, en “Tiempo y validez", Análisis lógico y derecho, Madrid, Centro de Estudios Constitucionales, 1991, pp. 198 y 199.

8 En su artículo sobre "El concepto de vigencia en Alf Ross", Bulygin observa que más que una predicción como sostiene Ross, la vigencia es "una predicación de una propiedad disposicional de ser aplicada en determinadas circunstancias". Análisis lógico y derecho, cit., nota 7, pp. 345, 346.

9 Raz señala que: "A Momentary Legal System Contains all the Laws of a System Valid at a Certain Moment ", en Raz, Joseph, The Concept of a Legal System, An Introduction to the Theory of Legal System, Oxford, Clarendon Press, 1970, pp. 34 y ss. 
aplicación retroactiva de normas que pudieran causar un perjuicio.

En el siguiente apartado se especificará el sentido en que el término validez es utilizado en el presente ensayo, lo cual permitirá conferir mayor claridad al modelo de sistema jurídico y contribuirá a la comprensión de la operatividad de las normas jurídicas en el tiempo.

\section{LA VALIDEZ TEMPORAL DE LAS NORMAS JURÍDICAS}

Como es sabido, la regla general en cuanto a la validez de las normas jurídicas en relación con su ámbito temporal es que son expedidas con el objeto de regular situaciones futuras, por lo que su exigibilidad es en principio solamente pro futuro. Las normas jurídicas válidas (prima facie) pueden producir efectos durante el lapso de su vigencia, ésta puede encontrarse regulada de manera específica por la propia norma en sus artículos transitorios, o supletoria por disposiciones generales del sistema jurídico, y puede ser limitada o indefinida. En los casos en que el ámbito de validez temporal no sea determinado, las normas serán válidas en tanto no sean derogadas.

Como es bien sabido, de la regla general sobre la operatividad en el tiempo de las normas se derivan dos excepciones: la retroactividad y la ultraactividad. A la primera se le conoce más bien, por el principio general de derecho que establece que las normas jurídicas no deben aplicarse retroactivamente en perjuicio de persona alguna. Este principio constituye una limitación al legislador, mas no un impedimento para la aplicación retroactiva de las normas, cuando justificadamente así es determinado por el sistema. La segunda excepción ha sido menos controvertida, a pesar de que implica la aplicación de normas derogadas, ya que tiene por función la preservación de derechos específicamente determinados.

Para poder explicar la operatividad temporal de las normas jurídicas a partir del modelo que permite distinguir en- 
tre sistema y orden jurídicos, es necesario distinguir entre los conceptos de pertenencia y vigencia, así como entre validez y existencia y los diversos significados que estos conceptos pueden tener.

Existen diversos conceptos de validez, el sociológico que se refiere al cumplimiento de la norma o aplicación de la sanción, al cual nos referiremos al hablar de la eficacia de la norma; el ético, que alude a su vigencia moral, la cual deriva de la justificación moral de cada norma, así como del sistema jurídico en su conjunto, y el jurídico, el cual de conformidad con la concepción positivista, se refiere a que la norma ha sido creada conforme a las disposiciones respectivas del sistema jurídico. ${ }^{10}$ El objetivo del presente apartado es exclusivamente desentrañar el significado del concepto jurídico de validez. La validez en sentido normativo implica que la aceptación, aplicación y acatamiento de la norma son obligatorios.

El término validez no solamente es ambiguo, sino que en la teoría y la filosofia del derecho, ha sido utilizado para referir distintos fenómenos relativos a las normas jurídicas, ${ }^{11}$ lo cual ha conducido a innumerables disputas, algunas de ellas tan sólo aparentes en mi opinión. Así por ejemplo, Eugenio Bulygin en el intento de delimitar el concepto de validez en su ensayo sobre "Tiempo y validez",12 se ocupa tan sólo de dos de los posibles significados que él denomina "pertenencia” y "aplicabilidad". En el caso de la pertenencia, Bulygin considera a la validez como un concepto descriptivo, dado que se refiere a un hecho. Pero cuando el término "válido" se refiere a la obligatoriedad de la norma, sostiene que puede tener dos significados, el primero como

10 Alexy hace una evaluación de estos conceptos en El concepto y la validez del derecho, cuyo objetivo no es determinar el sentido del concepto de validez, sino del derecho y su validez (Barcelona, Gedisa, 1997, pp. 87 y ss.).

11 Ensayos relevantes que se ocupan del problema de la definición del concepto de validez son los de Ross, Alf, El concepto de validez y otros ensayos, 3a. ed., México, Fontamara, 1997, pp. 8-29; Nino, Carlos Santiago, La validez del derecho y otros ensayos, Buenos Aires, Astrea, 1985 y de Bulygin, Eugenio, "Validez y positivismo", Análisis lógico y derecho, cit., nota 7, pp. 499-519.

12 Op. cit, nota 7, pp. 195-214. 
"prescripción de obedecer y aplicar" que se configura como un concepto normativo de validez, y el segundo, que para Bulygin describe el hecho de que una norma es obligatoria de conformidad con otra norma. ${ }^{13}$ A este último caso lo considera un tercer concepto de validez al que llama "aplicabilidad", el cual en su opinión, solamente afirma la existencia de una norma conforme a la cual otra norma debe ser aplicada a un caso. En consecuencia, para Bulygin hay tres conceptos de validez, dos descriptivos relativos a la pertenencia y aplicabilidad de las normas y uno normativo, que se refiere a su fuerza vinculante.

La distinción que hace Bulygin así, tiene sentido en la medida en que permite diferenciar los enunciados que pertenecen al sistema de los que no; de tal forma que en realidad cuando se utiliza el término validez dentro del sistema se hace en sentido normativo, esto es, en relación con su obligatoriedad. No obstante, el término validez cuando refiere "aplicabilidad", es para mí un enunciado normativo, por lo tanto, tiene carácter prescriptivo cuando es la autoridad la que establece que una norma $x$ debe ser aplicada en un caso $y$. Este es el caso de las determinaciones sobre la aplicación retroactiva o ultraactiva de una norma, por ejemplo, que pueden ser determinadas por el legislador o un juez con carácter vinculante.

Si el término validez en sentido normativo es el término genérico con el cual se califica jurídicamente a una norma, entonces debe cuestionarse el momento a partir del cual se le reconoce existencia a una norma, lo cual en principio, ocurre desde que entra en vigor. La vigencia es la condición que permite a la norma producir consecuencias jurídicas, ${ }^{14}$ esto es, derechos u obligaciones, la cual debe diferenciarse de la aplicabilidad, ya que no constituye una cualidad de la norma, sino un efecto de su validez (prima facie o definiti-

13 Ibidem, pp. 195 y 196.

14 Ross sostiene que la validez indica que un acto jurídico puede producir las consecuencias jurídicas que prevé; Ross, Alf, Directives and Norms, Londres, Routledge and Kegan Paul, 1968, p. 104. 
va). La vigencia es condición de validez de la norma; ocurre únicamente después de la culminación del proceso de producción de la norma con la publicación, una vez que se cumple el plazo o condición para que sea exigible.

La validez por lo tanto, no forma parte de la norma y se refiere a su obligatoriedad, de tal forma que en este modelo de análisis es posible sostener que la validez no condiciona la pertenencia, sino la aplicación de la norma. Esto se debe a que la validez de las normas se presume, puesto que no toda norma vigente es necesariamente válida, por lo que al introducirse al sistema se integran con una presunción de validez en su favor; esta forma de validez es la que es calificada como prima facie. ${ }^{15}$

La validez "definitiva" en cambio, depende del cumplimiento del proceso de creación establecido, así como de los contenidos regulados, lo cual se refiere a su validez formal o material, respectivamente. Es un atributo de la norma que indica su obligatoriedad y aplicabilidad. La validez formal depende de la regularidad del proceso de creación de las normas, en un sistema jurídico organizado jerárquicamente depende por lo tanto, de los criterios de ordenación de los cuales derivan reglas de validez. La validez material, de conformidad con la teoría de Kelsen,16 depende, en cambio, de la adecuación del contenido de la norma inferior a la superior, y en última instancia, de la norma suprema. Pero a pesar de que la validez en sentido normativo pueda ser evaluada conforme a dos criterios, una norma solamente puede ser considerada plenamente válida si cumple con ambos.

La validez es un atributo que no se puede comprobar $a$ priori, por lo que para reforzar su aceptación y obediencia,

15 Kelsen, Hans, Teoría general del derecho y del estado, traducción de Eduardo Garcia Máynez, México, UNAM, 1988, pp. 189 y ss. Asimismo, sostiene Kelsen que en última instancia, las leyes inconstitucionales no son nulas de antemano, sino que solamente pueden ser anuladas, Allgemeine Staatlehre, Bad Homburg v.d. Höhe, Berlín, Zürich, Verlag Dr. Max Gehlen, 1925 (1966), p. 255.

16 Kelsen, Hans, Teoría pura del derecho, 2a. ed., traducción de R. Vernengo, México, Porrúa, 2000, p. 232. 
se presume su validez en tanto no sea cuestionada formalmente por los medios que el propio sistema jurídico establece, esto es, como una validez prima facie, de tal forma que las normas creadas conforme al procedimiento establecido se reputan válidas. La validez definitiva en cambio, implica la existencia de una declaración formal de validez por el órgano competente, y su consecuencia es que la norma es plenamente obligatoria y aplicable, o en otras palabras, su aplicación es obligatoria. Es a este tipo de validez a la que Bulygin denomina "aplicabilidad", el caso en que la autoridad emite una norma que obliga a la aplicación de la norma a la que se refiere.

La validez sólo se pierde por disposición de una norma expresa, en consecuencia no se pierde por falta de eficacia, a menos que la desuetudo esté reconocida con fuerza derogatoria por el sistema jurídico. ${ }^{17}$ La derogación es una función de las normas, que tiene por objeto terminar con la validez de otra norma, pero la norma derogada a pesar de que pierde su fuerza normativa y su vigencia, no deja de pertenecer al sistema jurídico. Esta última afirmación es la que puede parecer un tanto contradictoria con los principios tradicionales de operatividad temporal del sistema jurídico, pero se sostiene en el modelo de sistema jurídico en que se puede hacer una relativización temporal para distinguir las normas aplicables en un momento determinado, de las que ya no lo son.

La derogación tiene por efecto limitar la aplicación de otras normas al privarla de su vigencia, ésta puede referirse a una privación total o parcial de la validez de la norma. La total elimina la norma del orden jurídico, la parcial restringe la aplicación de la norma a casos específicos conforme a lo previsto en las disposiciones correspondientes, es decir, los artículos transitorios que autorizan una especial forma

17 Como bien señala Leticia Bonifaz en su obra sobre El problema de la eficacia en el derecho, para los formalistas la eficacia no afecta ni la validez ni la existencia de la norma, a diferencia de lo que opinan los realistas (México, Porrúa, 1993, pp. 16-18). 
de validez temporal. De tal modo, que la norma derogada puede ser por excepción expresa, válida para uno o varios casos específicos. ${ }^{18}$

Las normas derogatorias pueden ser agrupadas en la categoría de reglas de adjudicación de Hart, ${ }^{19}$ dado que establecen la vigencia o reglas de aplicación temporal de otras normas. Podría parecer que estas normas se refieren a otras normas, pero en realidad se trata de normas que se dirigen a las autoridades obligadas a aplicarlas, por lo tanto, pueden configurarse, a diferencia de las reglas de competencia, como reglas de aplicación. La derogación impide la futura aplicación de una norma y la posibilidad de que produzca efectos jurídicos al destruir su vigencia, pero no elimina la norma del sistema, en otras palabras, no afecta su pertenencia, aunque le impide pasar al siguiente orden jurídico. ${ }^{20}$

Vigencia y eficacia son dos conceptos que se deben distinguir a pesar de que se relacionan con la obligatoriedad de la norma, dado que no se presentan necesariamente en una norma al mismo tiempo. ${ }^{21}$ La vigencia, como ya se mencionó, es un requisito formal para que la norma produzca consecuencias jurídicas, es por lo tanto, un criterio jurídico que determina la exigibilidad de la norma, pero la vigencia no garantiza su eficacia. La eficacia es un fenómeno sociológico, un criterio extranormativo de valoración de la obediencia y aceptación de la norma, y en última instancia, de su capacidad para producir efectos jurídicos, no una propiedad de la norma. El concepto de eficacia, como seña-

18 Uno estudio más amplio sobre la derogación puede ser consultado en Huerta, Carla, "Artículos transitorios y derogación", Boletín Mexicano de Derecho Comparado, México, núm. 102, 2001, pp. 811-840.

19 Hart, op. cit., nota 3, pp. 99 y ss.

20 Normalmente, y tal como lo señalan Alchourrón y Bulygin, una norma pasa de un orden jurídico al otro en virtud de la cláusula de supervivencia siempre y cuando no sea derogada o declarada formalmente inválida, seminario sobre "Los problemas lógicos de los sistemas normativos" impartido en el ITAM en México en agosto de 1991, inédito.

21 Aunque como señala Leticia Bonifaz, normalmente existe la pretensión de su coincidencia, op. cit., nota 17, p. 27. 
la Leticia Bonifaz, en general se refiere a la aplicación de la norma, a su observancia o a la realización de sus efectos. ${ }^{22}$ Por lo que es posible considerar que tanto el proceso de creación, como la eficacia son condiciones de validez de la norma, pero no la validez misma.

Los conceptos de existencia y pertenencia también deben se diferenciados a pesar de que ambos se encuentran referidos a los modos en que las normas se insertan o eliminan del sistema. El concepto de existencia no debe entenderse como una referencia ontológica, sino normativa que tiene relación con las reglas de introducción de la norma al sistema. La pertenencia se determina a partir de una norma de identificación o reconocimiento, que normalmente se puede identificar con normas de competencia. Ésta es una norma compleja que se integra por los procesos de creación y de control de la validez de las normas.

La pertenencia significa que la norma es considerada miembro del sistema y por lo tanto, puede producir efectos jurídicos, por que es vigentes o porque se permite su ultraactividad. En esos casos se puede considerar como obligatoria, pero en sentido débil, lo cual significa solamente que la norma puede producir efectos jurídicos, su validez es por lo tanto, tan sólo prima facie. La validez definitiva en cambio, implica una obligatoriedad en sentido fuerte. Pero la pertenencia de una norma al sistema jurídico no depende de su validez o eficacia, sino de la satisfacción de las condiciones mínimas de creación de las normas que le permiten ser introducidas al sistema. Por lo que desde su entrada en vigor asume una pretensión de validez que se encuentra condicionada a que no sea derogada la norma, no obstante, la pertenencia de una norma, una vez que se inserta en el sistema jurídico, no depende de su vigencia. Una norma derogada al perder su vigencia deja de pertenecer al orden jurídico, pero no al sistema La pertenencia de una norma al orden jurídico solamente indica que es aplicable, no que sea válida (en sentido normativo de regularidad), y menos 
aun, que su aplicación sea obligatoria (validez definitiva). En este mismo sentido señala von Wright, que la existencia de las normas depende de su expedición, pero su validez depende de otras circunstancias. ${ }^{23}$

La pertenencia de las normas a un sistema jurídico está asociada a su criterio de identificación (norma fundamental, regla de reconocimiento, por ejemplo) y se integra por sus reglas de introducción, generalmente aquellas relativas a la competencia normativa, o lo que en término comunes se conoce como el sistema de fuentes. ${ }^{24}$

La existencia de la norma, en sentido amplio, puede ser entendida como formulación, ${ }^{25}$ aceptar un mínimo de existencia a la formulación normativa que aún no ha completado su proceso de creación, o a la que solamente le queda por cumplir con las condiciones para ser vigente, permite explicar la realización de actos jurídicos respecto de esos enunciados normativos, como pueden ser actos de control de constitucionalidad previo o su derogación. La existencia en sentido restringido, depende de la vigencia de la norma, ya que sólo a partir de ese momento puede producir consecuencias jurídicas. ${ }^{26}$ Por lo que se puede afirmar que la vi-

23 Wright, G. H. von, "Bedingungsnormen, ein Prüfstein für die Normenlogik", Theorie der Normen, Festgabe für Ota Weinberger zum 65. Geburtstag, W. Krawietz et al. (eds.), Berlin, Duncker und Humblot, 1984, pp. 452.

24 Alchourrón y Bulygin consideran que a cada sistema normativo corresponde solamente un criterio de identificación, y para ellos, éste se integra por las reglas de introducción, así como las de eliminación, en Sobre la existencia de las normas jurídicas, México, Distribuciones Fontamara, 1997, p. 63. El concepto de reglas de eliminación fue expresamente substituido en el texto por el de control de validez, pues a pesar de que las reglas de eliminación forman parte de la regla de reconocimiento, en mi opinión, no tienen como consecuencia la supresión de la pertenencia de la norma al sistema, sino solamente la suspensión de su aplicabilidad en grados diversos.

25 Alchourrón y Bulygin señalan en su artículo "Norma jurídica", que en los casos en que la existencia se entienda como formulación es posible admitir que existen normas que no son vigentes, ni obligatorias, y que incluso no pertenecen al orden jurídico en sentido estricto, porque o bien han sido formuladas con "propósitos prescriptivos", o son consecuencias lógicas de normas asî formuladas; en Garzón Valdés y Laporta (eds.), El derecho y la justicia, Enciclopedia Iberoamericana de Filosofía, Madrid, Trotta, 1995, p. 138.

26 Quizá es en este sentido en que von Wright afirma que la existencia de las normas depende del lenguaje, pero se podría decir que aunque sea una condición 
gencia es una condición necesaria de la existencia (s.s.), así como de la pertenencia de la norma al orden jurídico, a diferencia de las normas cuya existencia como formulación se admite, que no pertenecen al sistema jurídico.

Numerosos autores se han ocupado de la existencia de las normas, pero también en sentidos diversos. ${ }^{27}$ La existencia puede identificarse como hace von Wright con la duración temporal y establecerse como equivalente a la duración de la relación ente la autoridad normativa y el sujeto regulado, la cual se equipara así a su vigencia. ${ }^{28}$ Para poder aceptar esta tesis, la relación mencionada no puede considerarse como dependiente del conocimiento del sujeto normativo de la norma expedida. Esta relación incluso puede considerarse como si se iniciara con la publicación de la norma, aun cuando no haya entrado en vigor, y a pesar de que aun no puede producir efectos jurídicos, la norma si es susceptible de ser objeto de otros actos jurídicos, como control de constitucionalidad previo, derogación o reforma.

La existencia también puede ser entendida como legalidad, ${ }^{29}$ en este sentido, habría que cuestionarse el momento en que el procedimiento de creación se perfecciona. Algunos autores consideran que la promulgación es el último acto, para otros es la publicación, pero la mayoría considera que además debe de entrar en vigor la norma para poder considerar que existe. De tal forma que la posibilidad de producir consecuencias dependería de la existencia en este senti-

necesaria, no es suficiente. Norm and Action, Londres, Routledge and Kegan Paul, 1963, p. 94.

27 Entre otros, Alchourrón y Bulygin, Sobre la existencia de las normas juridicas, cit., nota 24. Al igual que en "Norma jurídica", en Garzón Valdés y Laporta (eds.), El derecho y la justicia, Enciclopedia Iberoamericana de Filosofía, cit., nota 25, en su artículo "Validez y positivismo", Alchourrón y Bulygin refieren cuatro conceptos de existencia: existencia fáctica, pertenencia, como validez y el formal, que se refiere a admitir que la formulación de una norma tiene un mínimo de existencia; Análisis lógico y derecho, cit., nota 7, pp. 508-510.

28 Von Wright, op. cit., nota 26, p. 118.

29 Aun cuando ésta se considera normalmente asociada más bien al concepto de validez que al de existencia de la norma, lo cual podría llevar en casos extremos a confundir existencia y validez, tesis que Kelsen afirma de manera explícita en op. cit., nota 16 , p. 23. 
do. Alchourrón y Bulygin consideran que la promulgación es (la única) condición necesaria y suficiente de la existencia de la norma, ${ }^{30}$ por lo que se puede asumir que con ello lo que afirman es una existencia mínima, no plena, como formulación simplemente. Para ellos, es posible hablar de la existencia temporal de las proposiciones con sentido normativo en relación con su pertenencia a un sistema jurídico, siempre y cuando éste sea dinámico. ${ }^{31}$ Así, "si la existencia de una norma es definida en términos de pertenencia de una determinada norma-sentido a un determinado sistema de normas", se obtiene un concepto temporal de existencia. ${ }^{32}$ Esto se debe a que para ellos el criterio genético es descriptivo, refiere un hecho, pero aclaran que esta noción de existencia no es gradual, ya que una norma pertenece o no a un sistema. 33

Las anteriores afirmaciones se sostienen en una concepción hilética ${ }^{34}$ de las normas, que como José Juan Moreso ${ }^{35}$ bien señala, se sustenta en una definición semántica de la norma jurídica: las normas son el significado de los enunciados normativos. De tal forma que para poder sostener la existencia de una norma, bastaría con que fuese expresable lingüisticamente, como sería el caso de las consecuencias lógicas que existen en el sistema y forman parte de él, a pesar de que no hayan sido formuladas de manera explícita por la autoridad. Sin embargo, en mi opinión, más que su

30 Alchourrón y Bulygin, agregan como condición para que la promulgación dé lugar a la existencia de una norma, que el acto de promulgar la norma sea "serio", lo cual puede significar la simple voluntad normativa o autoridad en sentido estricto, esto sin embargo no es claro en el texto. Sobre la existencia de las normas juridicas, cit., nota 24, p. 31 .

31 Como las normas-sentido son abstractas, su existencia es atemporal según estos autores, de tal forma que para relativizar temporalmente la existencia de las normas utilizan el concepto de pertenencia, ibidem, p. 61.

32 Idem.

33 En "Norma jurídica”, en Garzón Valdés y Laporta (eds.), El derecho y la justicia, Enciclopedia Iberoamericana de Filosofía, cit., nota 25, p. 137.

34 Esta distinción se atribuye a Alchourrón y Bulygin y la hacen también en su libro Sobre la existencia de las normas juridicas, cit., nota 24, pp. 41-44.

35 "Lenguaje jurídico", en Garzón Valdés y Laporta (eds.), El derecho y la justicia, Enciclopedia Iberoamericana de Filosofía, cit., nota 25, p. 106. 
existencia, lo que se puede afirmar así, es su pertenencia al sistema.

La validez de la norma es determinada por el sistema jurídico, no se infiere lógicamente, y como atributo tiene distintos alcances, por lo que podemos estar de acuerdo en que este concepto tiene al menos dos sentidos: aplicabilidad y legalidad. La validez como pertenencia es la que podemos llamar "validez prima facie", y constituye tan sólo una presunción de validez y presupuesto de aplicación de las normas. La validez en este sentido se relativiza cuando una norma deja de ser "válida", porque otra norma resulta aplicable. El sentido del concepto de validez cambia completamente cuando surge obligación de aplicar la norma, así la validez se vuelve definitiva y ya no puede ser cuestionada.

La validez definitiva es un concepto que surge de la posibilidad de hacer una distinción en cuanto a la obligatoriedad del mandato de aplicación que sostiene a la norma. En los casos en que la obligatoriedad de la norma es revisada para determinar su aplicabilidad para el caso específico, su validez se puede ver afectada en distintos grados: la inaplicación, la declaración de invalidez y la declaración de nulidad, siendo el menor el primero y el mayor el último. La validez definitiva implica la obligación de aplicar la norma, son mandatos de aplicación que explicitan el concepto de validez normativa. De tal forma que la validez definitiva se sustenta en una norma jurídica, los enunciados de validez pronunciados por la autoridad competente son normas jurídicas sobre la validez de una norma que tiene efectos vinculantes, por lo que se consideran obligatorias. Son, por ende, prescripciones en sentido estricto.

De tal forma que es posible redefinir la noción de pertenencia, para sostener que una norma pertenece al sistema jurídico, cuando su aplicación puede ser considerada. La validez como capacidad de producir efectos jurídicos puede asociarse al concepto de pertenencia que constituye una 
clase más amplia. El concepto de existencia como formulación a su vez, es aún más amplio que los dos anteriores.

Una vez hechas las anteriores precisiones conceptuales, es preciso reflexionar sobre el alcance de la facultad de la autoridad para modificar la operatividad en el tiempo de las normas y cuáles son sus límites, esto es, si puede determinar la operatividad ultraactiva o retroactiva de una norma y cuál sería su significado para el sistema jurídico.

\section{VALIDEZ TEMPORAL Y ARTÍCULOS TRANSITORIOS}

No es el objeto del presente apartado abundar en cuestiones específicas relativas a la naturaleza y función de los artículos transitorios, ${ }^{36}$ sino solamente por lo que se refiere a las formas extraordinarias de operatividad temporal de las normas jurídicas. Este tipo de disposiciones se encuentran normalmente en los artículos transitorios, los cuales en virtud de su forma, son normas que integran el sistema juridico, regulan conductas y las establecen como obligatorias, prohibidas o permitidas. Su relevancia radica en que en este tipo de normas es posible establecer como obligatoria la aplicación temporal diferenciada, ya sea retroactiva o ultraactiva de una norma.

Los artículos transitorios son considerados como normas jurídicas en sentido estricto, en virtud de que comparten la misma estructura que las demás normas: supuesto, cópula y sanción, entendida esta última como consecuencia jurídica, ya sean derechos u obligaciones. La diferencia respecto de otros tipos de normas radica en dos aspectos importantes, primero en que el sujeto normativo es una autoridad y no un particular, y segundo, en que su objeto se refiere a la vigencia o modo de aplicación de las normas que regulan. Si bien es cierto que en virtud de su naturaleza se podría decir que los artículos transitorios son normas que se refie-

36 La naturaleza y función de los artículos transitorios ha sido analizada previamente en relación con la derogación en el artículo citado en la nota 18. 
ren a otras normas, esto no es totalmente cierto, ya que el sujeto normativo no son las normas aun cuando se determine su vigencia, sino las autoridades que las han de aplicar. Por lo que siguiendo a Alchourrón y Bulygin, ${ }^{37}$ se podría decir que forman parte del sistema del juez en sentido amplio, más que del súbdito.

Los artículos transitorios cuando se refieren a la aplicación transitoria de otra norma pueden establecer reglas de aplicación diferenciada a los sujetos normados sin que por ello se atente en contra de los principios de generalidad de las normas o de legalidad. La supervivencia temporal de las normas derogadas es permitida por un sistema jurídico como un recurso de justicia para permitir su aplicación a casos pendientes de resolución y así, impedir la vulneración de derechos adquiridos.

De conformidad con lo señalado en el apartado precedente, es posible afirmar que los artículos transitorios existen (l.s.), desde el momento de su publicación, aun cuando no hayan entrado en vigor y por ello no pueden ser considerados como obligatorios, no obstante, se les debe reconocer un minimo de existencia como formulación con el objeto de poder realizar actos jurídicos respecto de ellos, aun antes de entrar en vigor. Esto permitiria hacer una valoración sobre la oportunidad de las determinaciones en cuanto a la validez temporal extraordinaria de ciertas normas.

Existen tres clases de artículos transitorios: los que regulan la vigencia de una norma, los que establecen un mandato al legislador ${ }^{38}$ y los que establecen la derogación de una o varias disposiciones jurídicas, poniendo así, fin a su vigencia. En relación con la validez temporal de las normas, solamente se analizan los artículos transitorios que especifican el modo de aplicación de una norma, mismo que se

37 Alchourrón y Bulygin, op. cit., nota 2, capítulo VIII.

38 El mandato al legislador es según la tipología en Scheuner, una norma que prevé un contenido específico: la obligación del legislador de regular una determinada materia o disposición, Scheuner, Ulrich, "Staatszielbestimmungen", Festschrift für Forsthoff, Beck, München, 1972, pp. 325-346. 
puede referir a la retroactividad o ultraactividad de una norma.

Los artículos transitorios que determinan una forma especial de aplicación temporal de una norma se encuentran generalmente vinculados a normas derogatorias, las cuales prohíben a la autoridad la aplicación de las disposiciones derogadas y, por ello, jamás pierden su vigencia. Algunos artículos transitorios que establecen la derogación y regulan la aplicación de las normas nuevas, mantienen parcialmente vigentes algunas disposiciones para ciertos fines. Solamente si se hace la distinción entre sistema y orden jurídicos en los términos de su operatividad como diacrónico y sincrónico respectivamente, es posible aceptar la coexistencia de normas vigentes y derogadas, ya que así es posible distinguir el conjunto de normas que pertenecen al sistema jurídico de las que son aplicables a un caso dado.

Como se mencionó previamente, los artículos transitorios que regulan la aplicación retroactiva o ultraactiva de una norma tienen en mi opinión, la misma estructura que cualquier otra norma jurídica, por lo que serán analizados conforme al modelo de von Wright. ${ }^{9}$ Para él, las normas se integran por seis elementos: carácter, contenido y condición de aplicación que constituyen el núcleo normativo, esto es, la estructura lógica que las normas jurídicas tienen en común con otras normas, y por ciertas características específicas de las normas jurídicas que son el sujeto (normativo), la autoridad que las emite y la ocasión.

Por lo que al núcleo normativo se refiere, el carácter de una norma depende del tipo de deber que califica el acto o acción, esto es, al modo en que la conducta regulada es calificada jurídicamente, y es representado por un operador deóntico que establece una conducta como prohibida, permitida u obligada. Los artículos transitorios prescriben a la autoridad obligaciones en relación con la aplicación de otras disposiciones. Esta obligación es exigible de la autoridad que deberá aplicar las normas a las que se refiere, así

39 Von Wright, Norma y acción, Madrid, Tecnos, 1979, pp. 87 y ss. 
como de las autoridades que o bien deben de dejar de aplicar las disposiciones que se derogan, o que deberán continuar aplicando las disposiciones derogadas por los transitorios por un tiempo determinado o de conformidad con la condición que se establezca.

El carácter de los artículos transitorios que se refieren a la aplicación temporal diferenciada de una norma es por una parte de obligación, ya que la autoridad competente deberá aplicar la norma más allá de su ámbito temporal de vigencia, y por la otra, de prohibición (de aplicar las normas expedidas a los casos especificados). En consecuencia, es posible afirmar que este tipo de artículos transitorios prevé más de una norma. Es más, para poder hacer una excepción a la aplicación de las disposiciones derogatorias en los artículos transitorios es necesaria una autorización expresa cuyo contenido sería la facultad para la aplicación temporal de las normas derogadas en relación con los casos especificados en los artículos transitorios. Esta autorización se configura como un permiso que opera como una excepción específicamente delimitada en el tiempo y por el objeto a que se refiere, a lo previsto en la norma derogatoria. En realidad, estas disposiciones tienen la misma naturaleza que las normas de competencia.

Según von Wright, el contenido se refiere a "aquello que debe o puede o tiene que hacerse o no hacerse", 40 es decir, a la conducta regulada, ya sean acciones u omisiones genéricas, estados de cosas o cambios. En el caso de los artículos transitorios relativos a la validez temporal de las normas, éstos deben referirse exclusivamente a su vigencia, a la aplicación de las normas, así como a la determinación específica de las normas que pueden considerarse como exigibles a pesar de haber sido derogadas y los supuestos en que deberá admitirse su ultraactividad, o bien, a los su-

40 Von Wright divide, desde el punto de vista de su contenido, las normas en: concernientes a la acción (actos, normas positivas, y abstenciones, normas negativas) y normas concernientes a la actividad, ibidem, p. 88. 
puestos específicos en que a la norma promulgada se le podrán dar efectos retroactivos.

La condición de aplicación también forma parte del núcleo normativo, en términos de von Wright se refiere "a aquella condición que tiene que darse para que exista oportunidad de hacer aquello que es el contenido de una norma dada", ${ }^{41}$ esto es, a aquello que tiene que ocurrir para que se materialice la conducta regulada. Se podría decir que son los estados de cosas o acciones que deben verificarse para que la norma sea aplicable. En el caso de los artículos transitorios que regulan la aplicación de las normas en el tiempo, la condición de aplicación generalmente es un plazo o una condición. Las que determinan la aplicación retroactiva de una norma o la ultraactividad contienen además de la condición de aplicación prevista en su contenido, otras condiciones adicionales relativas a los casos en los cuales es posible modificar la validez temporal de una norma o aplicar normas derogadas. En términos de von Wright, éstas serian "hipotéticas" por su condición de aplicación. ${ }^{42}$

Von Wright define al sujeto de una prescripción como "el agente (o agentes) a quienes la prescripción se dirige o se da", ${ }^{43}$ esto es, a quienes se les impone alguna forma de deber, y pueden ser particulares o generales. De modo que si por sujeto normativo se entiende al titular de las obligaciones este tipo de normas sólo pueden regular las conductas de las autoridades, no a los individuos como se señalaba al hablar del carácter de la norma. Serían generales según su clasificación en virtud de que se dirigen a todas las personas sin restricción, ya que no se especifica a un individuo. El modelo de análisis de von Wright resulta sumamente útil para distinguir lo que es regulado, la validez temporal, del

41 Ibidem, p. 90.

42 Desde el punto de vista de su condición de aplicación von Wright, divide las normas en categóricas e hipotéticas, en las primeras la condición de aplicación se encuentra en su contenido, es decir, el supuesto de hecho, las segundas, en cambio, contienen otra condición adicional en su formulación además del contenido, idem.

43 Ibidem, p. 93. 
sujeto a quien se dirigen las normas, es decir, la autoridad aplicadora, misma que puede ser regulada conforme a una determinada descripción, sin por eso menoscabar el carácter general de la norma.

La ocasión se refiere a las circunstancias en que el contenido de la norma ha de realizarse, específicamente, al lugar y tiempo previstos en la disposición jurídica. Según la ocasión, von Wright las clasifica en particulares y generales. ${ }^{44}$ Son particulares las que se refieren a una sola ocasión o a un número finito de éstas; son generales en cambio, las que prevén un número ilimitado de ocasiones. Los artículos transitorios que determinan la aplicación temporal de normas derogadas para la resolución de casos pendientes, son consideradas, en términos de von Wright, como particulares en relación con la ocasión. ${ }^{45}$ Lo mismo ocurre con las disposiciones que determinan la aplicación retroactiva de una norma a hechos ocurridos con anterioridad o casos pendientes de solución. El lugar depende del propio ámbito de validez espacial de la norma derogada en el caso de la ultraactividad o de la norma promulgada en el caso de la retroactividad, y el tiempo de vigencia deriva del contenido de la norma en virtud de su naturaleza.

La autoridad es un elemento propio y distintivo de las normas jurídicas según von Wright, este concepto se refiere al agente que emite la norma, en principio los artículos

44 Cabe señalar que von Wright designa a una norma particular, sólo si es particular en relación con el sujeto y la ocasión, y general, si es general en relación con el sujeto o la ocasión, y si ambos son generales, entonces las llama eminentemente generales. En consecuencia, en realidad, las normas que determinan la validez temporal serian generales según su clasificación. Ibidem, p. 97.

45 Esto podría parecer ser conforme con la tesis de Jacques Herón, quien sostiene que la determinación de retroactividad en una disposición hace que "mute" la norma y se transforme de regla en una "serie de decisiones". En su opinión, las normas retroactivas pierden su carácter abstracto al determinar la norma derogatoria casos específicos de aplicación, por lo que de general pasaría a ser considerada como particular (aunque no utiliza los términos en el mismo sentido que von Wright), e incluso pierden su carácter hipotético. En realidad, considero que siguen siendo abstractas y generales, solamente que su generalidad se limita, y se reduce a menos casos de los que la norma preveía antes de que el artículo transitorio alterara su validez temporal. Principes du droit transitoire, Dalloz, 1996, pp. 53-59. 
transitorios son emitidos por un "agente empírico impersonal”, según su propia clasificación. ${ }^{46}$ Por la autoridad, las normas que regulan la validez temporal son heterónomas, ya que quien realizar la acción normativa y el sujeto a quien se dirigen son distintos, aun cuando, como ya se mencionó, ambos tengan el carácter de autoridad, pues son sujetos distintos.

En conclusión, las normas que regulan la validez temporal de otras normas son emitidas por órganos de autoridad facultados (con ciertas restricciones previstas en el propio sistema jurídico, como por ejemplo, el principio de no retroactividad) para regular y modificar la validez temporal de las normas jurídicas y se dirigen a otros órganos con autoridad para aplicarlas, sujetándolos así en sus decisiones a las normas especificadas por los artículos transitorios. Su contenido sólo puede referirse a la vigencia y la determinación específica de la aplicabilidad de las normas en el tiempo, y pueden ser consideradas como particulares en relación con la ocasión, mas no con el sujeto.

\section{LA RETROACTIVIDAD}

A pesar de la gran cantidad de escritos relacionados con este tema, la retroactividad del derecho sigue presentando serios cuestionamientos. Saber que el término se refiere a la operación en el tiempo de una norma que le permite tener eficacia respecto de las consecuencias juridicas de hechos sucedidos previamente a su expedición, no resuelve todas las dudas. Que una norma pueda ir hacia el pasado no es completamente cierto, lo que realmente sucede es que la disposición jurídica en cuestión es considerada válida para el caso específico, aun cuando los hechos hubiesen ocurrido antes de entrar en vigor. Se crea una ficción, y se pretende que la norma se mueve en el tiempo hasta el mo-

46 Esto significa que la existencia del agente natural es contingente o empírica y que el emisor de la norma es una persona legal o jurídica, no un individuo en específico. Von Wright, Norma y acción, cit., nota 39, pp. 55, 56 y 92. 
mento de los hechos, como si entonces ya hubiese estado vigente.

En realidad lo que ocurre es que se hace una excepción a la aplicabilidad de la norma vigente en el momento en que ocurrieron los hechos para que sean valorados conforme a una norma posterior, inexistente entonces, pero que preserva mejor los valores de seguridad jurídica y justicia. En este mismo sentido se han expresado muchos autores ${ }^{47}$ para quienes una de las finalidades primordiales del derecho es la seguridad jurídica, la cual se conforma por diversos principios como son el de prohibición de la retroactividad de las leyes penales, así como de aquellas que pudieran causar un perjuicio a las personas, que de haber conocido las consecuencias jurídicas de sus actos, probablemente no las hubiesen realizado.

La no retroactividad de las normas jurídicas no se funda en la naturaleza del derecho, es por ello que no existe una regla general, sino que su aplicación tiene variantes según las distintas ramas del derecho. Para poder comprender este fenómeno deben plantearse dos preguntas: ¿qué es? y ¿cómo opera la retroactividad? Lo cual se refiere en última instancia a la aplicación legítima de ciertas normas jurídicas fuera de su ámbito de validez temporal.

La relevancia de la regulación de la aplicación retroactiva de una norma radica en que implica la posibilidad de modificar o suprimir las consecuencias jurídicas de un hecho ocurrido durante la vigencia de una ley que ya ha sido derogada. Según la tesis de Roubier, misma que considero la más adecuada para explicar la retroactividad, una norma tiene efectos retroactivos cuando se aplica a hechos consumados durante la vigencia de una disposición jurídica anterior, o a situaciones jurídicas que se encuentran aun en

47 Así lo afirma Zippelius por ejemplo, en relación con Bentham; Zippelius, Reinhold, Teoría general del Estado, 2a. ed., México, Porrúa-UNAM, 1989, p. 279. 
proceso de verificación, en relación con los efectos producidos antes de la entrada en vigor de la nueva ley. ${ }^{48}$

Esta forma de operatividad temporal constituye una excepción a la regla general de vigencia, que tiene por objeto evitar un perjuicio derivado del cambio dado en la legislación entre el momento de la realización de los hechos y el de la aplicación de la norma a través de una resolución. En principio, una norma jurídica es aplicable solamente a partir del cumplimiento de la condición o término previstos en los artículos transitorios para su entrada en vigor, antes de ello ni siquiera es juridicamente existente (s.s.). Por ello, es que se ha establecido un principio de derecho en relación con la retroactividad que impide la aplicación de disposiciones a casos ocurridos con anterioridad a la expedición de una norma. El principio de no retroactividad regula a la autoridad, y como bien dice Jacques Herón, si el legislador debe abstenerse de dar efecto retroactivo a las normas jurídicas, con mayor razón debe abstenerse el juez de conferirles tal carácter. ${ }^{49}$

El principio de no retroactividad es reconocido universalmente por los sistemas jurídicos modernos; se encuentra previsto en el artículo 14 de la Constitución Política de los Estados Unidos Mexicanos, que establece que "a ninguna ley se dará efecto retroactivo en perjuicio de persona alguna". Este artículo no prohíbe la retroactividad de las normas jurídicas, sino solamente la limita y determina que en caso de tener que aplicar una norma jurídica general con efectos retroactivos debe hacerse de tal forma que no se perjudique a persona alguna, ya que en el caso de que alguien resultara afectado negativamente en sus intereses, la disposición no podrá aplicarse retroactivamente. Esta es la regla general, a la cual existen diversas excepciones y especificidades que se dan por materia, por lo que para una mejor comprensión del fenómeno de la retroactividad vale la

48 García Máynez, Eduardo, Introducción al estudio del derecho, México, Porrúa, 1977, p. 393.

49 Herón, Principes du droit transitoire, cit., nota 45, p. 64. 
pena revisar los diversos criterios sostenidos por la Suprema Corte.

El primer aspecto a destacar es que cabe la posibilidad de hacer una interpretación a contrario sensu y pensar que en caso de ser benéfica la aplicación retroactiva, ésta debe de hacerse. 50 Sin embargo, esta interpretación constituye más bien una excepción, que una regla general, por lo que la jurisprudencia ha establecido diversos criterios en este sentido. En consecuencia, deben hacerse algunas precisiones, puesto que no es obligación de la autoridad buscar la disposición más benéfica, sino en virtud de los principios de legalidad y seguridad jurídica fundar su decisión en una disposición jurídica válida. Por lo tanto, el afectado no puede solicitar que se le aplique otra disposición jurídica que convenga mejor a sus intereses, ya que la garantía prevista en el artículo 14 constitucional se refiere a evitar un perjuicio, no a producir beneficios.

En ese sentido, la siguiente jurisprudencia en materia fiscal es muy clara, y prevé que la retroactividad es inoperante cuando sea favorable al causante:

...La citada garantía debe entenderse como el derecho del gobernado a reclamar la inconstitucionalidad de cualquier ley que se le pretenda aplicar retroactivamente en su perjuicio, pero no como un derecho para exigir que se le aplique determinada ley en forma retroactiva simplemente porque le favorezca, máxime en una materia como la fiscal en que las normas respectivas son de observancia estricta... ${ }^{51}$

Por otra parte, la subsistencia parcial y temporal de las normas derogadas para aquellos casos en que una persona pudiese resultar beneficiada por su aplicación, o en otras palabras, la ultraactividad tampoco deriva de una obliga-

50 Según Jacques Herón, el significado de la retroactividad in mitius significa que una infracción cometida con anterioridad, ya no sea castigada o lo sea menos severamente, op. cit., nota 45, p. 64.

51 RETROACTIVIDAD DE LA LEY. NO OPERA EN MATERIA FISCAL, AUN CUANDO SEA FAVORABle al CAUSANTE, Semanario Judicial de la Federación, Tribunales Colegiados de Circuito, 8a. época, t. I, segunda parte-2, enero-junio 1988, p. 605. 
ción constitucional por interpretación del artículo 14 . Cuando la intención del legislador sea modificar específicamente la validez temporal de ciertas normas jurídicas, esto debe preverse así de manera expresa en los artículos transitorios, ya que como previamente se mencionó, la interpretación a contrario sensu no es válida, y así se desprende también de la siguiente tesis jurisprudencial:

...si bien es cierto que el artículo 14 constitucional establece la garantía de la irretroactividad de la ley, cuando sea en perjuicio de alguna persona, del texto del propio artículo no puede desprenderse la existencia de una garantía en sentido contrario; esto es, la Constitución no obliga a que necesariamente se deban aplicar retroactivamente las leyes que introduzcan beneficios... 52

El criterio que prevalece en materia en penal, en cambio, es otro, ya que el objetivo es proteger valores superiores como la vida y la libertad, por lo que en virtud de una razón de mayor justicia, en esta materia es obligatoria la aplicación retroactiva que tenga el carácter de benéfica, ya que de otra manera se pueden causar daños irreparables. ${ }^{3} \mathrm{Sin}$ embargo, debe hacerse una aclaración, ya que tanto la jurisprudencia como la doctrina han distinguido los casos en que la retroactividad es procedente, uno de los criterios ha sido la función de la disposición jurídica, por lo que dependiendo de si ésta es adjetiva o sustantiva, prevalecen criterios diferentes. 54

52 IRRETROACTIVIDAD, GARANTÍA DE. NO OBLIGA A APLICAR RETROACTIVAMENTE LA LEY CUANDO BENEFICIA A UN PARTICULAR, Semanario Judicial de la Federación, Tribunales Colegiados de Circuito, 8a. época, t. V segunda parte-1, junio de 1990, p. 266.

53 Retroactividad DE LA LEY, Semanario Judicial de la Federación, Tribunales Colegiados de Circuito, 8a. época, t. XIII, mayo de 1994, p. 529.

54 Retroactividad De las leyes De PROCEDimientos, Semanario Judicial de la Federación y su Gaceta, Tribunales Colegiados de Circuito, 9a. época, t. II, agosto de 1995, XVI, 2 o -1 K, p. 614. RETROACTIVIDAD. APLICACIÓN IMPROCEDENTE DE LA LEY PROCESAl PENAL, Semanario Judicial de la Federación, Tribunales Colegiados de Circuito, 8a. época, t. XII, agosto de 1993, p. 554. 
Así, se ha previsto en la jurisprudencia que en el caso de normas penales de procedimiento no puede darse efectos retroactivos a la ley, aunque cause un perjuicio; uno de los argumentos ha sido que se trata de normas de orden público. Pero en realidad se debe a que a pesar de que un proceso penal se haya iniciado antes de las reformas, al entrar en vigor rigen las situaciones jurídicas en el estado en que se encuentren los juicios, puesto que los procesos penales se desarrollan mediante actos sucesivos, no en un sólo momento. 55

Además, mediante la interpretación del artículo 14 constitucional, la jurisprudencia ha establecido una garantía aún más amplia a la prevista en la Constitución siguiendo la definición tradicional de los derechos fundamentales como derechos subjetivos de defensa frente al Estado. Así, resulta que la aplicación retroactiva de la ley benéfica solamente es obligatoria antes de que se dicte la sentencia, sea de primera o segunda instancia.56 $\mathrm{Si}$ la ley es reformada con posterioridad y resulta más benigna, corresponde su aplicación a la autoridad ejecutora, ${ }^{57}$ pero además no procede recurso alguno contra la autoridad judicial, ya que ésta resolvió conforme a derecho. ${ }^{58}$ Asimismo, la jurisprudencia ha establecido que en dichos casos no se produce infracción alguna de las garantías individuales del sentenciado. 59

En consecuencia, la regla general que rige para las autoridades judiciales es resolver conforme a la ley vigente, sal-

55 Código Federal de Procedimientos Penales, iRRetroactividad DE LA LEy EN TRATÁNDOSE DE REFORMAS AL, Semanario Judicial de la Federación, Tribunales Colegiados de Circuito, 8a. época, t. IX, febrero de 1992, p. 151.

56 APlicación Retroactiva DE LA LEY PENAL. PRIMER TRIBUnAl COlEGIAdo DEL DÉCIMO SEGUNDO CIRCUITO, Semanario Judicial de la Federación, 8a. época, t. XIV, julio de 1994, primera parte, p. 434.

57 Idem.

58 RETROACTIVIDAD DE LA LEY PENAL MÁs FAVORABle. CASO EN QUE SU

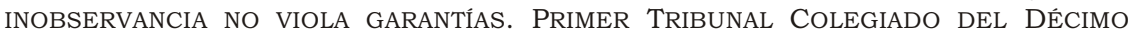
PRIMER CIRCUITO, Semanario Judicial de la Federación, 8a. época, t. I, enero-junio de 1988, segunda parte-2, p. 605.

59 Idem. 
vo por los aspectos sustantivos en materia penal que constituye una excepción. Para las autoridades administrativas en cambio, la obligación radica en tomar en consideración las reformas que entren en vigor cuando de su aplicación pudiera derivarse un beneficio para el sentenciado. Esto se debe a que la garantía de no retroactividad es una garantía de seguridad jurídica, cuyo fin es limitar la actividad del poder público para que la esfera de derechos del particular no se vea afectada. En consecuencia, la aplicación retroactiva en beneficio del gobernado tiene el carácter de garantía de exacta aplicación de la ley, no obstante, “...cuando no se haya dictado sentencia ejecutoria corresponde a la autoridad judicial aplicar retroactivamente la ley en su resolución,...", 60 pero si con posterioridad a que la sentencia haya sido dictada entra en vigor una ley más favorable, corresponde su aplicación a las autoridades administrativas. ${ }^{61}$

El artículo 14 constitucional establece la garantía de irretroactividad, que como regla de aplicación de otras normas prevé que a una norma jurídica general no se le podrán dar efectos retroactivos cuando se perjudique a persona alguna. En dicho artículo al referirse a la no retroactividad, el constituyente utilizó el término "ley", el cual debe ser entendido en el sentido más amplio como norma jurídica general, y no simplemente como disposición emitida por el Congreso, ya que esto restringiría la garantía. Por otra parte, los órganos facultados no aplican leyes exclusivamente, en consecuencia este precepto se refiere a toda norma jurídica general.

En relación con lo expuesto, la jurisprudencia ha establecido que el significado de la retroactividad está vinculado a la operatividad y función de las leyes, puesto que esta garantía significa que en virtud de que toda disposición legal

60 RETROACTIVIDAD DE LA LEY PENAL. SI AL PRONUNCIARSE LA SENTENCIA DEFINITIVA NO ESTABA EN VIGOR LEY MÁS FAVORABLE. SU APLICACIÓN CORRESPONDE A LA AUTORIDAD EJECUTORA, Semanario Judicial de la Federación, Tribunales Colegiados de Circuito, 8a. época, t. XV-2, febrero, de 1995, Tesis II.2o. P. A. 256 P, p. 530.

61 ApliCACión Retroactiva de la ley PENAL, PRIMER TRIBUnAl Colegiado DEL DÉcimo SEgundo Circuito, Semanario Judicial de la Federación, 8a. época, t. XIV, julio de 1994, primera parte, p. 434. 
tiene una vigencia determinada en cuanto al tiempo y su permanencia depende de su creación y su derogación o abrogación expresa o tácita, su función es regular los actos y situaciones que tienen lugar durante ese lapso limitado por esos dos momentos. Por lo tanto, toda ley a partir del momento que entre en vigor rige para el futuro, en consecuencia “...una disposición legal no debe normar acontecimientos producidos con anterioridad al instante en que entró en vigor tal disposición, ya que éstos quedan al imperio de la ley antigua...". ${ }^{62}$ El término "debe" ha sido escrito en cursivas puesto que no implica una obligación, se refiere a un deber ser técnico63 más que deóntico, por lo que opera más bien como una sugerencia dirigida al legislador que con el carácter de obligatoriedad referido a la norma misma o a los órganos aplicadores.

Tanto la doctrina como la jurisprudencia han hecho énfasis en la necesidad de tomar en cuenta la estructura de la norma jurídica. Basándose en ella y en la teoría general de la acción, es que se pueden distinguir diversos momentos de la materialización del supuesto y de las consecuencias jurídicas para determinar si la aplicación retroactiva es conforme a derecho o no.

Aun cuando no ha ocurrido con la frecuencia deseada, en la jurisprudencia se ha utilizado el criterio del análisis estructural de la norma para determinar si una ley procesal cumple con la garantía de irretroactividad prevista en el artículo 14 constitucional. Como ya se indicó previamente, la estructura de las normas jurídicas se conforma por un su-

62 DiVORCIO; IRRETROACTIVIDAD DEL ARTÍCULO 253, FRACCIÓN XVIII DEL Código Civil (LEGISLACIÓn DEl EsTAdo DE MÉXICO), Semanario Judicial de la Federación y su Gaceta, Tribunales Colegiados de Circuito, 9a. época, t. II, septiembre de 1995, Tesis II, 1o. C.T.4.C., p. 547.

63 Von Wright llama deber ser técnico a aquello que en sentido "técnico" debe ser o que debe ser hecho, expresa una situación condicionada o una relación medio/fin, ya que al menos que una cosa sea hecha alguna otra será o no el caso. Se trata de un requerimiento, una necesidad práctica, que corresponde más bien a la expresión "tener que". Yo diria que se trata de una sugerencia o recomendación más que un deber ser en sentido normativo. "Ser y deber ser", en Garzón Valdés et al. (comps.), La normatividad del derecho, Barcelona, Gedisa, 1997, p. 102. 
puesto de hecho, una cópula y una sanción, entendida ésta como consecuencia jurídica. ${ }^{64}$ Es propio de estas normas que al materializarse el supuesto se produzca la imputación genérica, atribuyéndose así al sujeto normativo, los derechos y obligaciones correspondientes. Pero tanto el supuesto, como la sanción pueden materializarse en momentos diferidos en el tiempo. Esto sucede en el caso de supuestos y sanciones complejos, es decir, compuestos por diversos actos parciales. 65

De tal forma que la jurisprudencia ha establecido que "para resolver sobre la retroactividad o irretroactividad de una disposición jurídica es fundamental determinar las hipótesis que pueden presentarse en relación con el tiempo en que realicen los componentes de la norma jurídica". Senalando que en principio, y de manera general pueden darse las siguientes hipótesis:

1) Durante la vigencia de una norma jurídica se actualizan, de modo inmediato, el supuesto y la consecuencia establecidos por ella. En este caso, ninguna disposición legal posterior podrá variar, suprimir o modificar aquel supuesto o esa consecuencia sin violar la garantía de irretroactividad, atento a que fue antes de la vigencia de la nueva norma cuando se realizaron los componentes de la norma substituida.

2) La norma jurídica establece un supuesto y varias consecuencias sucesivas. Si dentro de la vigencia de esta norma se actualiza el supuesto y alguna o algunas de las consecuencias, pero no todas, ninguna norma posterior podrá variar los actos ya ejecutados sin ser retroactiva.

64 Aquí me refiero a la que es comúnmente denominada estructura lógica o ideal de la norma jurídica, cfr. Rupert Schreiber, Die Geltung von Rechtsnormen, Berlín-Heidelberg-Nueva York, Springer Verlag, 1966, pp. 9 y ss.; Larenz, Karl, Metodología de la ciencia del derecho, 4a. ed. (1979), traducción de M. Rodríguez Molinero, Barcelona, Ariel, 1994, p. 243; Engisch, Karl, Introducción al pensamiento jurídico, traducción de Ernesto Garzón Valdés, Madrid, Ediciones Guadarrama, 1967, pp. 46-52; Kelsen, Hans, Teoría pura del derecho, México, Editora Nacional, 1981, p. 48.

65 Schreier, Fritz, Conceptos y formas fundamentales del derecho, México, Editora Nacional, 1975 , pp. 145 y ss. 
3) La norma jurídica contempla un supuesto complejo, integrado por diversos actos parciales sucesivos y una consecuencia. En este caso, la norma posterior no podrá modificar los actos del supuesto que se hayan realizado bajo la vigencia de la norma anterior que los previó, sin violar la garantía de irretroactividad. Pero en cuanto al resto de los actos componentes del supuesto que no se ejecutaron durante la vigencia de la norma que los previó, si son modificados por una norma posterior, ésta no puede considerarse retroactiva. 66

Poder separar los elementos de la norma permite emitir una opinión aún más certera sobre los casos en que una norma tiene efectos retroactivos respecto de ciertos actos o situaciones. De tal manera que se pueda determinar los casos en que la aplicación retroactiva es válida, infringe una garantía constitucional o simplemente no puede calificarse como retroactividad.

Otro tipo de norma que vale la pena analizar para saber si produce efectos retroactivos, es la jurisprudencia. Por lo que al carácter de la jurisprudencia, su rango y eficacia en el tiempo se refiere, en el caso de una sentencia interpretativa, la interpretación hecha por la autoridad competente se integra a la norma interpretada como parte de la misma, de tal forma que adquiere la misma fuerza y rango que la norma interpretada. ${ }^{67}$ Esto se debe a la mutación, ${ }^{68}$ que según la doctrina alemana es el fenómeno jurídico que consiste en alterar el sentido del precepto constitucional (de la norma),

66 Retroactividad. El artículo 426, Fracción I, Del Código De ProceDIMIENTOS CIVILES PARA EL DISTRITO FEDERAL NO ES RETROACTIVO, Semanario Judicial de la Federación, Pleno, 8a. época, t. IV Primera parte, julio a diciembre de 1989, Tesis LI/89, p. 111.

67 Véase Huerta, Carla, "Interpretación y Reforma, Dialéctica o Dilema", 80 aniversario, Homenaje, Constitución Politica de los Estados Unidos Mexicanos, México, UNAM, Instituto de Investigaciones Jurídicas, 1997, pp. 159-177; "La jurisprudencia como técnica", Boletín Mexicano de Derecho Comprado, México, año XXXII, núm. 95, mayo- agosto de 1999, pp. 397-415.

68 Hesse, Konrad, Escritos de derecho constitucional, traducción de Pedro Cruz Villalón, 2a. ed., Madrid, Centro de Estudios Constitucionales, 1992, pp. 24, 28, 29,79 y ss. 
sin modificar el enunciado lingüístico (el enunciado normativo). De manera que el texto permanece inalterado mientras que la norma recibe otro significado, esto es posible si se parte de un concepto semántico de norma, esto es, que el enunciado expresa una norma. ${ }^{69}$ La mutación permite la variación del significado de la norma por el órgano competente, en el caso del principio de no retroactividad, la Suprema Corte de Justicia, por ser la única facultada para interpretar directamente la Constitución. En consecuencia, la jurisprudencia es norma y tiene carácter prescriptivo.

En el sentido formal, y atendiendo al órgano que la elabora, la jurisprudencia tiene el rango que deriva de su obligatoriedad, es decir, no puede ser modificada por las resoluciones que emita un órgano jerárquica o competencialmente subordinado. En el sentido material, el rango de la jurisprudencia depende del rango de la norma interpretada, igual que su existencia depende en principio, de la existencia de la norma que interpreta, y en los casos en que la interpretación se refiera a un precepto que solamente ha cambiado de ubicación en el sistema jurídico (de artículo o de cuerpo normativo), ${ }^{70}$ ésta subsiste, lo mismo cuando se refiere a cuestiones generales que se presentan en otras normatividades (principios generales o cuestiones procedimentales, por ejemplo). En otras palabras, la jurisprudencia se refiere al enunciado normativo, por lo que basta con que otro igual se encuentre en el sistema para considerar que la jurisprudencia continua siendo vigente.

La jurisprudencia ha reiterado en diversas ocasiones, y utilizando diversos criterios, que su aplicación no es re-

69 Esta distinción ha sido hecha y es aceptada por numerosos autores, cfr. Alexy, Theorie der Grundrechte, Frankfurt a. M., Suhrkamp, 1994, pp. 42, ss.; Sieckmann, J.R., "Semantischer Normbegriff und Normbegründung", ARSP, 80, Stuttgart, 1994, p. 228; Weinberger, C. y O., Logik, Semantik und Hermeneutik, München, Beck, 1979, pp. 20, 108; o von Wright, G. H., Norm and Action, Londres, Routledge and Kegan Paul, 1963, p. 95 ss., por ejemplo.

70 RETROACTIVIDAD, NO SE PRESENTA EN CASO DE QUE LA LEY DEROGADA Y LA VIGENTE CONTENGAN DISPOSICIONES IDÉNTICAS, Semanario Judicial de la Federación, Tribunales Colegiados de Circuito, 8a. época, t. XIII, junio de 1994, Tesis aislada, p. 662 . 
troactiva, ni va en contra de los derechos fundamentales. Esto se debe en parte, a lo mencionado anteriormente en relación con su carácter de significado de la norma, y en parte, a que el Poder Judicial ha considerado que la jurisprudencia no constituye legislación nueva ni diferente, sino que sólo es la interpretación correcta de la ley. En consecuencia, con la aplicación inmediata de una nueva jurisprudencia no se infringe el principio jurídico de irretroactividad en perjuicio del quejoso. ${ }^{71}$

Por lo que a los artículos transitorios se refiere, en realidad éstos no operan ni pueden operar retroactivamente, ya que no regulan conductas de particulares. Operan para el futuro, ya que su función es la de actuar como reglas de aplicación de otras normas. Sin embargo, son este tipo de disposiciones las que establecen la retroactividad de otras disposiciones, previendo sus límites y alcances en relación con su operatividad en el tiempo. Como se mencionaba anteriormente, son obligaciones que se dirigen a la autoridad aplicadora, dado que la no retroactividad es un principio general cuyo fin es evitar los abusos de autoridad, no son prohibiciones o permisiones para otras normas.

La retroactividad en el fondo, no es sino la posibilidad de aplicar normas que no estaban vigentes en el momento de los hechos, pero de conformidad con el principio de legalidad, y siguiendo los criterios de seguridad jurídica y justicia. Esto se puede explicar al recordar que las normas no dejan de pertenecer nunca al sistema jurídico. Por ello, distinguimos el concepto de orden jurídico, que nos permite cambiar de conjunto de normas conforme al criterio de aplicabilidad, por lo que incluye las normas vigentes, así como aquellas que por disposición expresa se consideran válidas específicamente para ciertos casos, aun cuando no sean vigentes. Así, si en materia penal resulta benéfica la norma

71 JURISPRUDENCIA. SU VARIACIÓN Y APLICACIÓN INMEDIATA NO IMPLICA VIOLACIÓN AL PRINCIPIO CONSTITUCIONAL DE IRRETROACTIVIDAD, Semanario Judicial de la Federación, Tribunales Colegiados de Circuito, 8a. época, t. VIII, noviembre de 1991, Tesis I.3o.C. J/22, p. 121. 
vigente en el momento de la realización de los hechos, el juez no aplicará la disposición obligatoria en el momento de la resolución, sino aquella que hubiese estado vigente cuando el supuesto jurídico se materializó a pesar de haber sido derogada, siempre y cuando no hubiese sido declarada nula. ${ }^{72} \mathrm{El} \mathrm{juez} \mathrm{recurre} \mathrm{entonces} \mathrm{a} \mathrm{un} \mathrm{orden} \mathrm{jurídico} \mathrm{diverso}$ que ya no está vigente, pero que en virtud de una disposición vigente del propio sistema jurídico resulta aplicable. Esto es viable porque la norma derogada no ha dejado de pertenecer al sistema.

Finalmente, considero que a la luz de la doctrina y de la jurisprudencia utilizando el modelo que permite distinguir entre sistema y orden jurídicos, no solamente se comprende mejor el funcionamiento de la retroactividad, sino que se preserva la unidad del sistema jurídico, así como las garantías de legalidad y seguridad jurídicas.

\section{CONCLUSIÓN}

La alteración de la regla general relativa a la validez temporal de las normas, esto es la posibilidad de dar efectos retroactivos o ultraactivos a una norma, se explica en el contexto de la dinámica del sistema jurídico y la operatividad de las normas en el tiempo. El modelo que distingue entre sistema y orden jurídicos permite mostrar como la aplicación retroactiva o ultraactiva de las normas se da dentro del propio sistema jurídico, sin tener que recurrir a una ficción, puesto que las normas aplicadas pertenecen al sistema independientemente de su vigencia específica en el momento de la aplicación.

Los artículos transitorios carecen de autonomía, esto es, solamente pueden existir en vinculación con otras disposiciones normativas y tienen por único objeto regular el ám-

72 La nulidad produce un efecto distinto en el sistema jurídico al de la derogación, ya que en estos casos, la norma queda impedida para producir cualquier tipo de consecuencia jurídica, además, la declaración de nulidad si afecta la pertenencia de la norma. 
bito de validez temporal de ciertas normas. El principio de no retroactividad se dirige en consecuencia, en primera instancia al legislador, quien no debe injustificadamente modificar la validez temporal de las normas, por lo que le impide establecer esta posibilidad en los transitorios cuando pueda causar un perjuicio.

La validez es una propiedad jurídico-positiva que hace obligatoria a la norma y depende de criterios jurídicos, no de su eficacia. Por eso, es que en un sentido muy amplio, se puede decir que las normas que operan ultraactivamente, son válidas a pesar de hacer sido derogadas, de no estar vigentes, ya que el propio sistema establece como obligatoria su aplicación. La aplicación de estas normas es posible, porque la norma no ha dejado de pertenecer al sistema. Con fundamento en los mismos argumentos se puede decir que la norma a la que se da efectos retroactivos es válida, aun cuando ni siquiera existía en el momento en que se verificaron los hechos que debe regular.

La validez en sentido normativo ha de entenderse como regularidad en el proceso de creación, y se puede decir que tiene dos niveles de eficacia, el primero es el que entiende a la validez en un sentido amplio, y se refiere a la presunción de validez o validez prima facie, que permite considerar a las normas como exigibles. El segundo, es el que se puede considerar como el concepto de validez en sentido estricto, y se refiere a la obligatoriedad de la norma que ha sido declarada válida por la autoridad competente. 